\title{
Using of carbon fiber fabric for reinforcement the walls of the aerated concrete blocks in buildings, constructed in seismic regions
}

\author{
Bulat Dzhamuev* \\ Moscow State University of Civil Engineering, Yaroslavskoe shosse, 26, Moscow, 129337, Russia
}

\begin{abstract}
We conducted experimental investigation of the strength masonry of aerated concrete blocks, reinforced by carbon fiber fabric. Reviewed various schemes of reinforcement. A comparison of the strength of non - reinforced walls with walls reinforced by carbon fiber are shown. Were carried out the tests of prototypes fragments of walls and the walls in life-size on the static and dynamic loads. According to the results of tests are given recommendations on the use of walls, reinforced by carbon fiber in seismic regions of Russia
\end{abstract}

\section{Introduction}

Using of walls of the aerated concrete blocks in the buildings, constructed in seismic regions of Russia is limited to the following reasons:

- masonry of the aerated concrete blocks, as well as brick masonry, is not regarded as a plastic material, and regarded as elastic (up to a certain level of load) or brittle (above this level.) Structures of plastic materials easily withstand some significant overload and in their calculation as the primary overload may be the average intensity of seismic action. Structures of brittle materials, including aerated concrete blocks, are very sensitive to the peaks of random overloads that for these structures may be critical. This is because the peaks overloading the most dangerous for brittle materials, whose elastic limit is closer to the limit of strength.

- using of ,mainly, cement mortar for masonry walls made of aerated concrete blocks does not allow the requirements of Seismic Building Design Code [1] to the masonry, in terms of its resistance to seismic effects: value of the normative traction should be Rtt $\geq$ $0,18 \mathrm{MPa}$ (for 1-st category masonry) and $0.18 \mathrm{MPa} \geq \mathrm{Rtt} \geq 0,12 \mathrm{MPa}$ (for 2-nd category masonry ).

When designing the walls of buildings from aerated blocks, questions of increasing strength and earthquake resistance of structures solved by the use of high-strength materials, special mortar, increasing the solidity of the masonry and reinforcement. Reconstruction of damaged structures, during earthquakes, carried out due to the use of constructive methods of reinforcement: reinforced concrete and steel cages or external reinforcement through the use of carbon fiber (fibre-reinforced polymer - FRP).

\footnotetext{
Corresponding author: dbk-07@mail.ru
} 
At the Center for Earthquake Engineering Research (hereinafter CEER) CSRIBS named after V.A. Kucherenko under the direction of the Head of laboratory of seismic Resistance of Structures, Ph.D in Engineering, Associate Professor Granovskiy Arkadiy developed and implemented a comprehensive program of experimental investigations of strength and deformability of load-bearing structures (walls and columns), made of aerated concrete blocks, ceramic brick and reinforced concrete, reinforced with FRP brand MBrace FIB CF («BASF»).

The purpose of research - evaluation of the effectiveness of carbon fiber fabric for increasing strength and rigidity of the bearing and enclosing structures of aerated concrete in buildings constructed in normal and in earthquake-prone regions of Russia.

The test program consisted of two phases:

- the 1-st stage, investigated the behavior of walls with various schemes of FRP reinforcement on static load: skew the wall in its plane;

- on the 2-nd stage of the dynamic tests were conducted with the opening in the all on vibroplatform, performed in full size. Tests were conducted on not reinforced and FRP reinforced samples.

\section{Materials of masonry and reinforcement}

For the fragments of masonry walls of prototypes used aerated concrete blocks, manufactured by technology YTONG closed joint-stock company «Ksella-AeroblockCentr» at class of concrete in B3.5 and a density of D500. A masonry wall was performed on the glutinous solution YTONG. For reinforcement the walls used the canvas of FRP brand MBrace FIB CF 230/4900.200g/5.100m.

As reference samples were used fragments of walls without reinforcement. In the test samples of first and third series reinforced by canvases of carbon fiber was carried out on both sides, in the test samples of second series - only on the one hand. On the figure 1 are shown scheme of the testing of prototypes. In each series, including reference samples has been tested three samples.

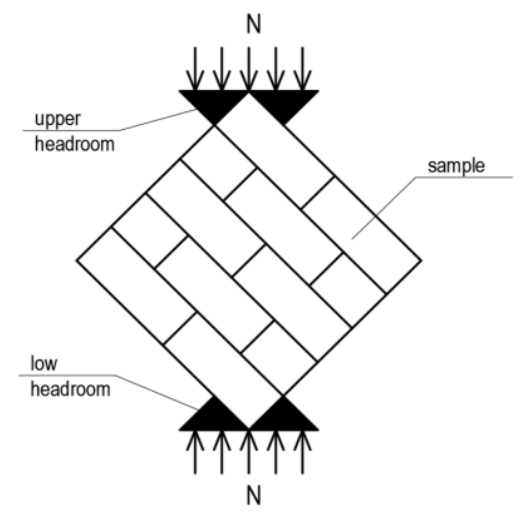

Fig. 1. Prototype test on sag.

\section{Static test on sag}

Preliminary tests (according to the scheme shown in figure 2) cubes, glued together by the glutinous solution brand «YTONG-economy», on the tensile (normal traction) and cut 
(tangential traction) have shown that the value of the normal and tangential traction of blocks amounted respectively Rtent $=0.2 \mathrm{MPa}$ and $\mathrm{Rcut}=1.07 \mathrm{MPa}$.

According to Seismic Building Design Code [1], for the masonry 1-st category temporary value of tensile strength should be Rtt $\geq 0,18 \mathrm{MPa}$. That is, masonry walls made of aerated concrete blocks "YTONG-economy» meets the requirements of Seismic Building Design Code [1] for the masonry walls of 1-st category.

In table 1 are shown the results of testing of prototypes. Test analysis of fragments of masonry walls of the aerated blocks YTONG produced by closed joint-stock company «Ksella-Aeroblock-Centr» on the glutinous solution brand «YTONG-economy», reinforced by carbon fiber brand MBrace (BASF), allows to note the following:

- limit of strength of masonry on cut, on the not-tied masonry joint, depending on the scheme of reinforcement, higher then strength not - reinforced by canvases of carbon fiber masonry in $1,34 \div 1,93$ times.

- traction of carbon fiber with aerated concrete block was provided before destruction of the masonry.
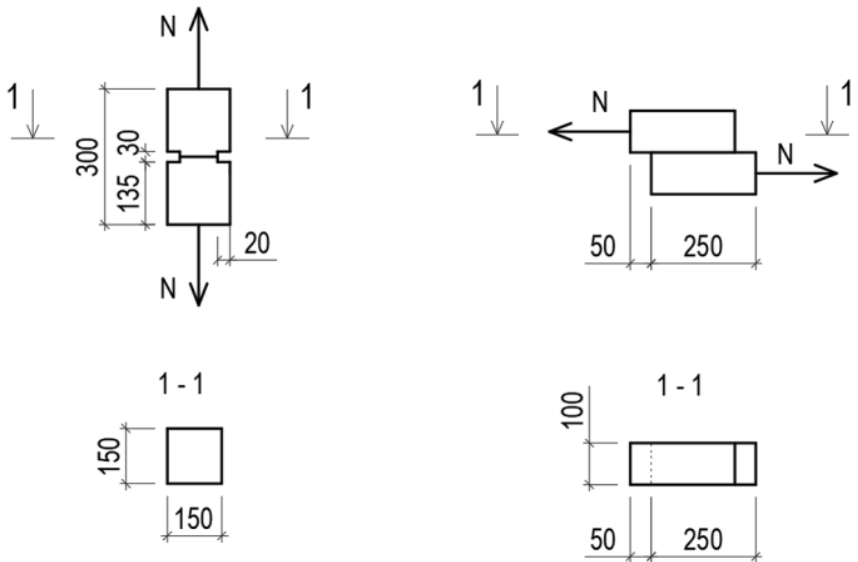

Fig. 2. Scheme of samples for testing on the tensile (normal traction) and cut (tangential traction).

Table 1. The results of testing of prototypes

\begin{tabular}{|c|c|c|c|c|}
\hline \multirow[t]{2}{*}{$\begin{array}{l}\text { No of } \\
\text { series }\end{array}$} & \multirow[t]{2}{*}{$\begin{array}{l}\text { Scheme of } \\
\text { reinforcement }\end{array}$} & \multirow[t]{2}{*}{$\mathrm{N}_{\text {dest }}, *(\mathrm{kN})$} & $\begin{array}{l}\text { Limit of masonry } \\
\text { strength on the cut } \\
\text { Rcut, }^{* *}(\mathrm{MPa})\end{array}$ & \multirow[t]{2}{*}{$\begin{array}{c}\text { Relative } \\
\text { strength, \% }\end{array}$} \\
\hline & & & $\mathrm{R}^{\exp }$ cut & \\
\hline Etalon & Nonreinforced & 174.6 & 0.67 & 100 \\
\hline I & $\begin{array}{l}3 \text { canvases on } \\
\text { both sides }\end{array}$ & 338.3 & 1.28 & 193 \\
\hline II & $\begin{array}{l}3 \text { canvases on } \\
\text { the one hand }\end{array}$ & 260.8 & 0.99 & 148 \\
\hline III & $\begin{array}{c}1 \text { canvas on both } \\
\text { sides }\end{array}$ & 206.3 & 0.79 & 134 \\
\hline
\end{tabular}

* - Mean values of the test results of 3 samples;

** -The value of the limit of strength of masonry on the bandaged cross section (column 5) Rcut determined by the formula:

$$
R_{\text {cut }}=N_{\text {dest }} /(1.4 \times a \times d)
$$


Where, Rcut - limit of strength of masonry on the not-tied masonry joint, MPa;

$\mathrm{N}_{\text {dest }}$ - the calculated value of the horizontal force, $\mathrm{kN}$;

a - half the length of the sample, m;

$\mathrm{d}$ - thickness of the sample, $\mathrm{m}$.

The conclusions of the tests on the sag:

- the walls of the aerated concrete blocks brand YTONG on the glutinous solution brand «YTONG-economy» meet the requirements of Seismic Building Design Code [1], imposed to the masonry 1-st category and can be recommended for use in seismic regions, with appropriate constructive and settlement justifications.

- increased strength and rigidity of the walls of the aerated blocks YTONG through the use of external reinforcement of carbon fiber fabric MBrace (BASF) can be recommended as the design of new structures, and in the process of reinforcement them.

\section{Dynamic tests}

In the second stage of testing was investigated the behavior of masonry walls of the aerated blocks (without reinforcement and with reinforcement by carbon fiber) under dynamic loads, simulating the effects of seismic intensity of 7-9 points, according to MSK-64 scale.

Dynamic tests were conducted on pre-compressed samples. The value of compression corresponded to $0.6 \mathrm{Rcomp}$. In the process of testing the value of compression was reduced to a minimum value, that is, until complete removal of the vertical load on the sample.

\section{Methods of testing}

To excite vibrations of fragment of the wall with the opening was used a test stand; the excitation of oscillations is performed using the VID-12 vibramachine, attached to a pendulum platform. Due to inertial forces developed by VID-12 vibramachine, provided a different frequency range of impacts on the test stand, and certain level of vibration amplitude. As shown the test, the maximum value of vibration amplitude of platform using VID-12 vibramachine is $150 \mathrm{~mm}$, the frequency range up to $75 \mathrm{~Hz}$.

Means of measuring and recording the dynamic characteristics of structures and impacts on them. Registration and measurement of signals were carried out using specialized measuring and computing complex MIC-036, designed for the collection, conversion, recording, processing, transmission and presentation of information from the sensors.

Measuring and computing complex MIC-036 additionally equipped with a laptop with specialized software packages and peripherals required to automate the processing of signals, and also for documenting the results of treatment.

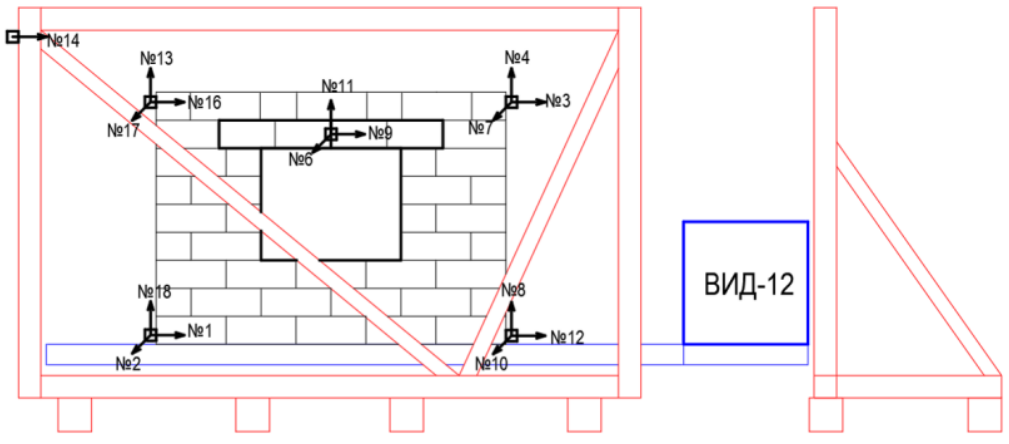




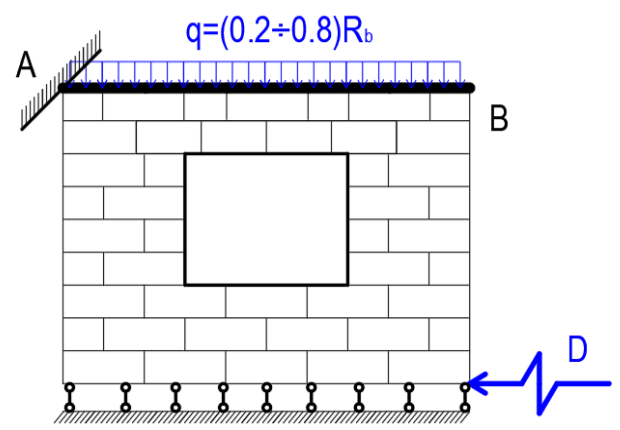

Fig. 3. Scheme of the prototype wall with an opening indicating the location of the accelerometers (a) and the boundary conditions for fixing the sample on the vibroplate platform (b).

To measure the acceleration, vibration frequencies, and also dynamic displacements are applied one-component sensors - accelerometers AT 1105-10m.

Points of the locations of the accelerometers are shown on figure 3.

If accelerations corresponds to the accelerations of the earthquake in 8 points and level of compression $0.2 \times$ Ndest there was a destruction of the etalon sample (fig. $4 a$ ).

If accelerations corresponds to the accelerations of the earthquake in 9 points on carbon fiber reinforced sample received a minor destruction: the break carbon fiber fabric and the appearance of cracks in horizontal masonry joints (fig. 4b).
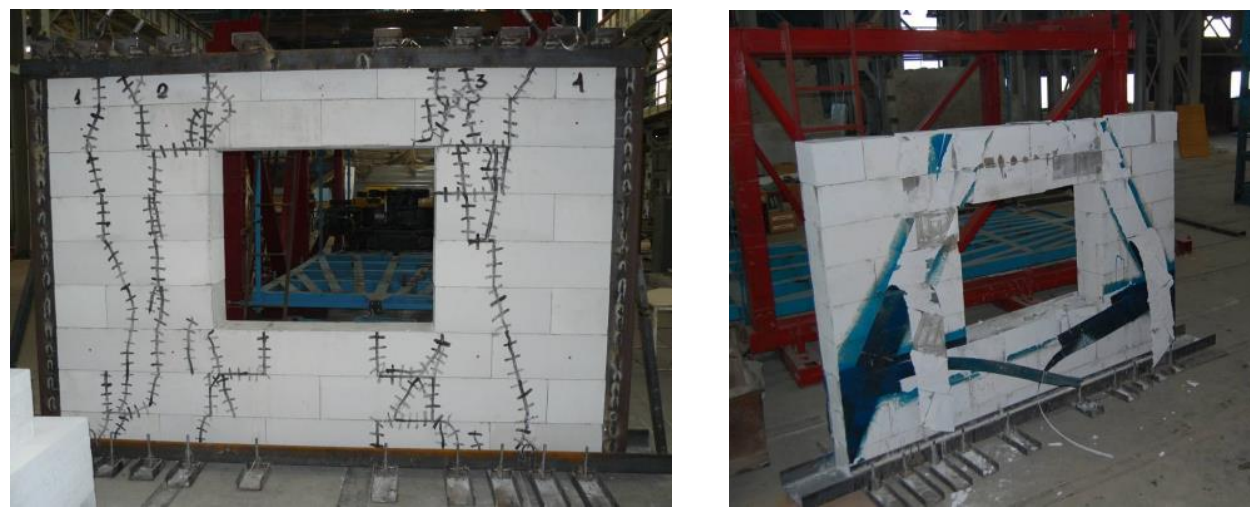

Fig. 4. General view of non-reinforced (a) and carbon-reinforced prototype wall (b) after testing.

\section{The conclusions}

Analysis of the results of numerous studies of seismic resistance of walls made of cellular concrete blocks [2-7], as well as the results of this research, allows us to recommend walls for use in the earthquake-prone regions of the Russian Federation of cellular concrete blocks manufactured by closed joint-stock company «Ksella-Aeroblock-Centr», made with YTONG technology on «YTONG-economy» glue mortar, reinforced with carbon fiber. 


\section{References}

1. Seismic Building Design Code - Set of rules 14.13330.2014 «Construction in seismic regions».

2. A.L. Mochalov, A.V. Granovsky, A.N. Kostenko, Industrial and civil construction, 7 (2006).

3. A. Aprile, A. Benedetti, E. Steli, E. Mangoni, FRPRCS-8 University of Patras (2007).

4. N. Uddin, F.H. Fouad, U.K. Vaidya, A.K. Khotpal, J.C. Serrano-Perez, Structural Journal, 6 (2007).

5. W. Raongjant, M. Jing, Structural Concrete, 1 (2009).

6. A.V. Granovsky, B.K. Dzhamuev, Journal of Industrial and Civil Engineering, 4 (2011).

7. A.A. Gasiev, A.V. Granovsky, B.K. Dzhamuev, Seismic construction and safety of structures, 3 (2015). 